\title{
Rancangan Sistem Informasi untuk dapat menghubungkan antara Donatur dan Penyandang Disabelitas
}

\author{
Putu Andrian Surya Indirva \\ Telkom University; \\ Email: andriansuryaputu1@gmail.com
}

\begin{abstract}
Sistem Aplikasi ini merupakan sebuah aplikasi yang di beri nama Benang Hati, dimana aplikasi ini diperuntukan untuk dapat mempermudah seorang donator untuk dapat memberikan bantuan kepada orang penyandang disabilitas, tujuan dibuatnya aplikasi ini adalah agar dapat mempermudah hubungan antara donator dan orang penyandang disabilitas sehingga nantinya lebih mudah dalam kejelasan informasi terkait dana.
\end{abstract}

Keywords: Bantuan , Donatur

Paper ini akan dipublikasikan di osf.io [1] menggunakan format standard perancangan sistem informasi [2]

\section{Introduction}

1.1. Business case

1.1.1 Project Definition: karena banyaknya bantuan ataupun membuka donasi untuk penyandang disabilitas, maka dari itu dibutuhkan sebuah website yang dapat menyatukan open donation dari satu organisasi ke organisasi lainnya.

1.1.2 Project Objective: system informasi ini bertujuan untuk menyebarluaskan informasi bantuan berupa ;lokasi yang membutuhkan bantuan, dan lain sebagainya.

1.1.3 System Definition: system yang dibutuhkan yaitu system yang dimana dapat mencocokan lokasi donator dengan lokasi penyandang disabilitas yang memerlukan donasi.

\subsection{System Requirement}

1.2.1 System Definition: system yang dibutuhkan adalah mencocokan lokasi donator dengan lokasi penyandang disabilitas agar dapat mempermudah penyaluran bantuan.

1.2.2 System Function: tujuan agar donasi ataupun bantuan yang diberikan bias merata di berbagai lokasi dan wilayah sehingga dapat memonitor secara langsung untuk mengetahui perkembangannya

1.2.3 System Features: Data Donatur, Alamat Donatur, Identitas Donatur, Wilayah Donatur 


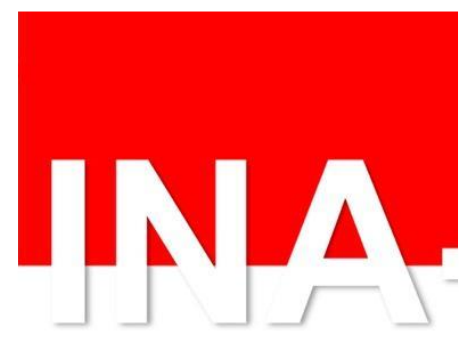

INDONESIAN

Figure 1 Contoh Gambar Indonesia

\section{Penjelasan SIngkat Terkait Metode}

Metode yang digunakan yaitu metode observasi pengumpulan data dengan melakukan pengawasan secara langsung dan mengumpulkan data requirement yang dibutuhkan untuk dapat menjalankan system.

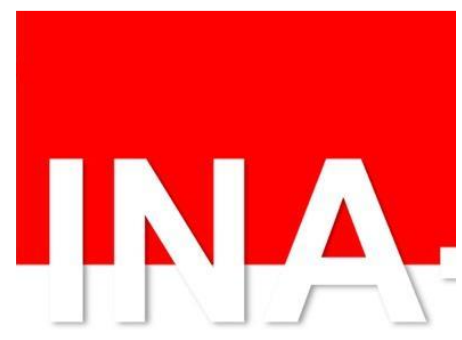

INDONESIAN

Figure 2 Contoh Gambar Indonesia

\section{Proses Perhitungan}

\subsection{System Design}

Berikut merupakan Struktur organisasi dan stakeholder pada system aplikasi Benang Hati

Tabel 2. Contoh Penlisan Tabel

\begin{tabular}{ccc}
\hline No & Nama & Jabatan \\
\hline 1 & Putu Andrian Surya & Ceo \\
2 & Pradipta ricky baskara & Koordinator Lapangan \\
3 & M.Rifky Fadhillah & Koor.RT\&Personalia \\
4 & Dimas Hartono & Administrasi \\
5 & Yuli irawan & User \\
\hline
\end{tabular}

3.2. Data Flow Diagram (DFD)

Berikut merupakan Data Flow Diagram Benang Hati 


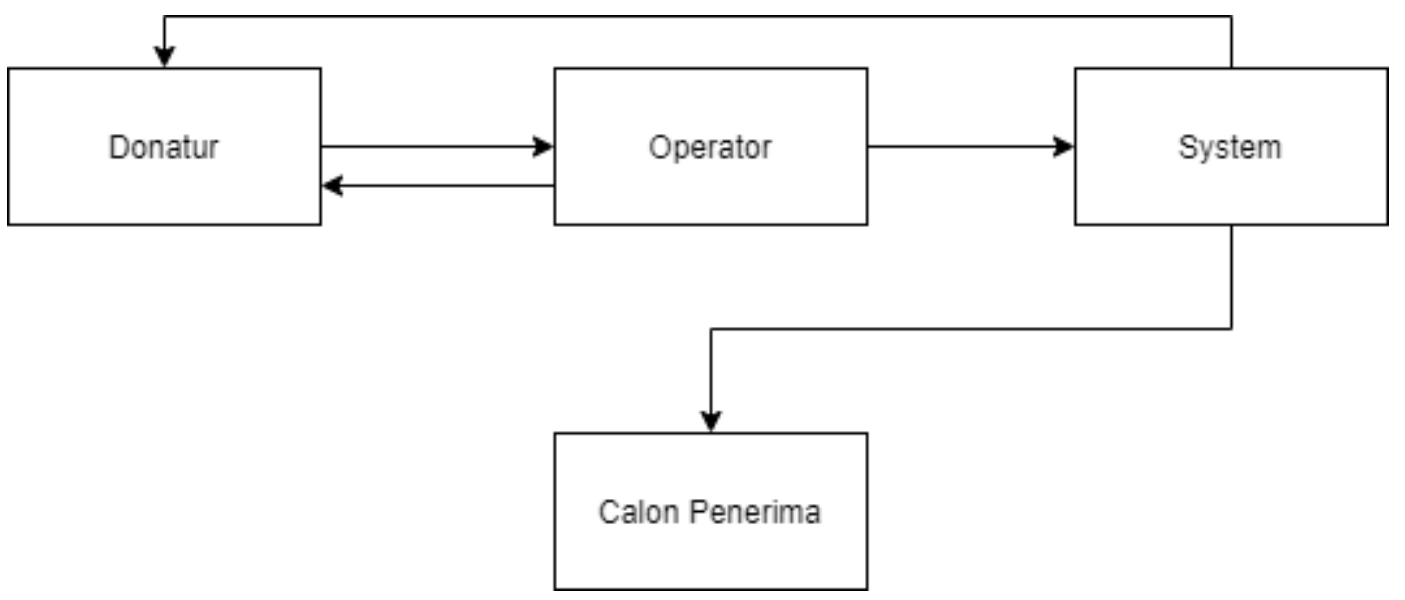

Figure 1 Gambar Data Flow Diagram

\subsection{Entity Relationship Diagram (ERD)}

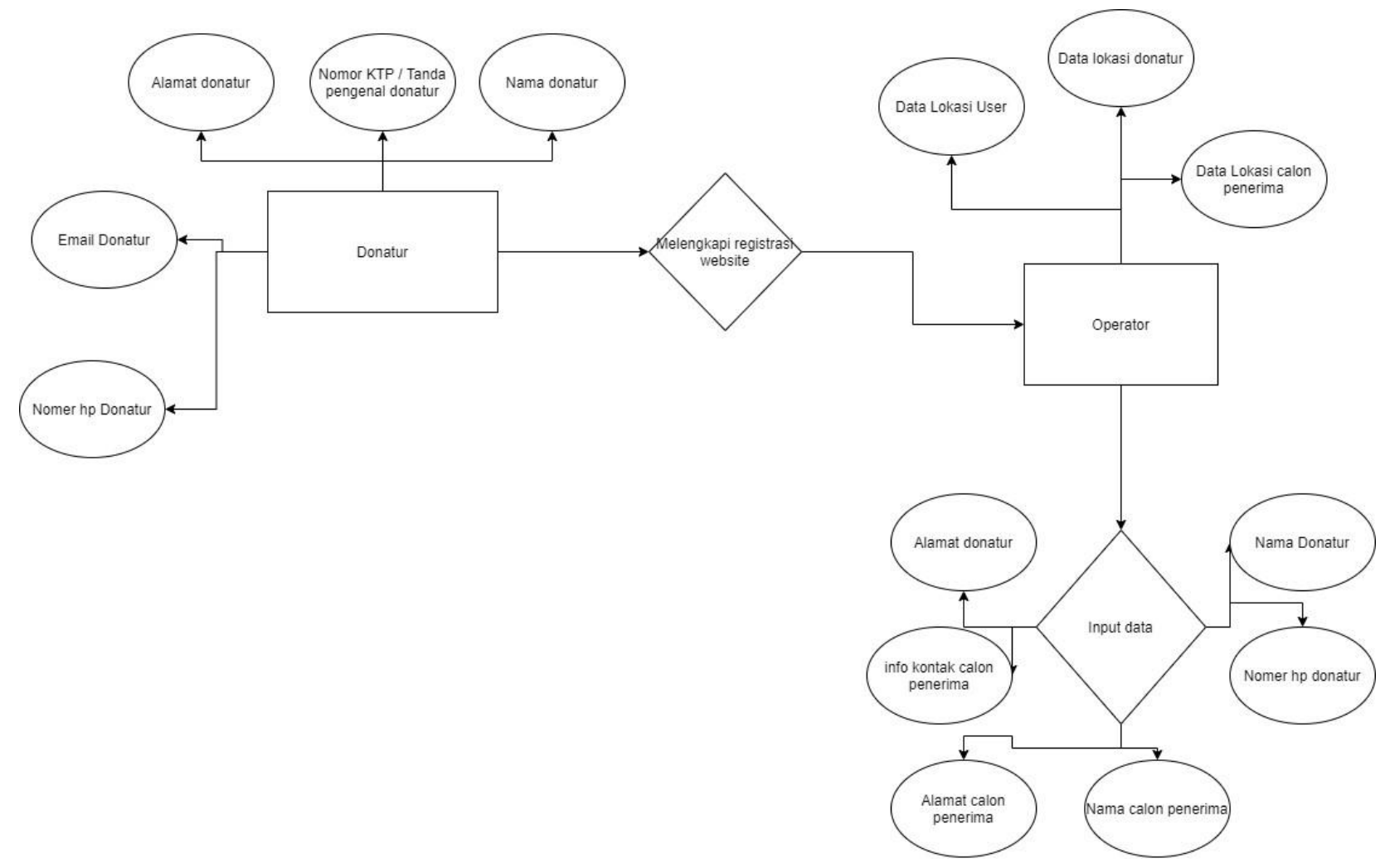

Figure 4 Gambar ERD

3.4. Database Design

Data Objects and File and Database Structures

3.5 Use Case Diagram

Berikut merupakan use Case Diagram Benang Hati 


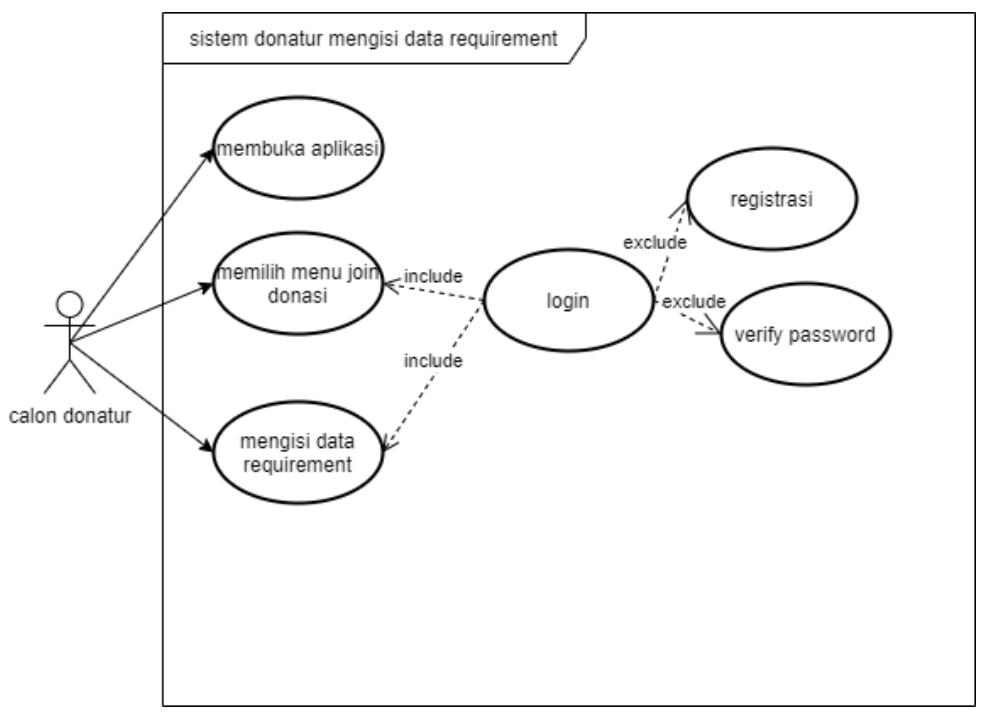

Figure 5 Gambar Use Case Diagram

\subsection{Activity Diagram}

Berikut merupakan activity diagram Benang Hati

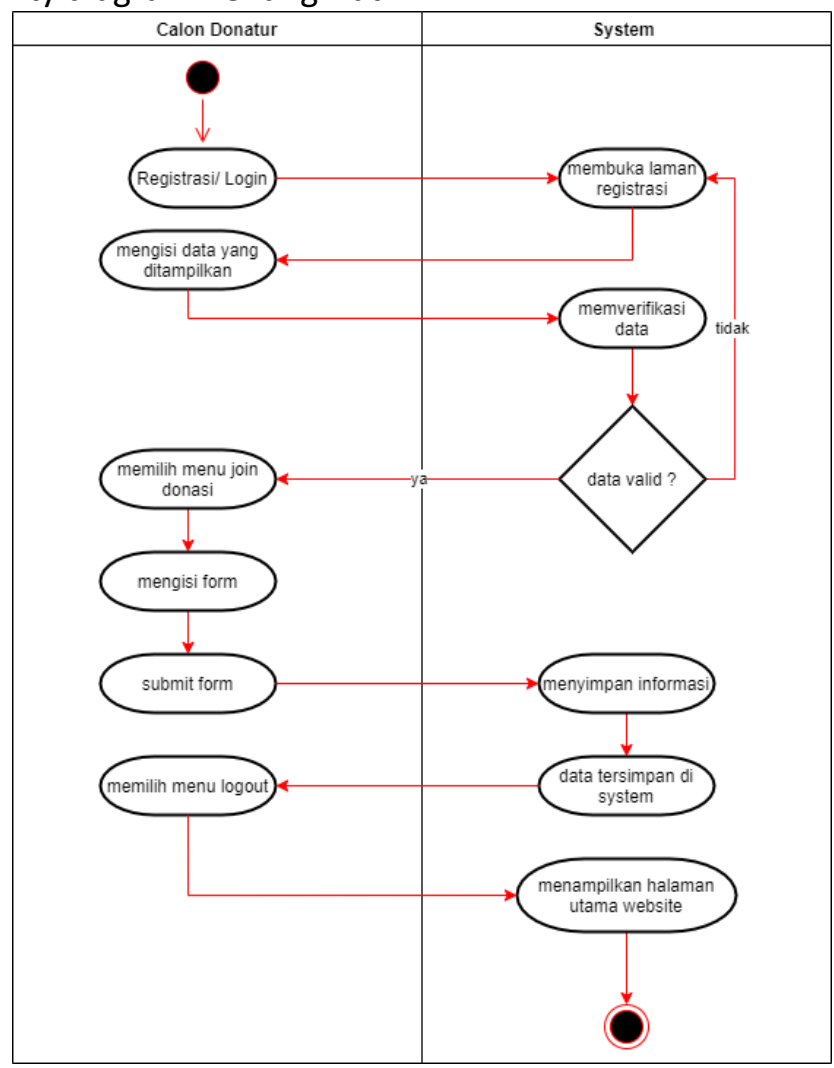

Figure 6 Gambar Activity Diagram

\subsection{Sequence Diagram}

Berikut merupakan Sequence Diagram Benang Hati 


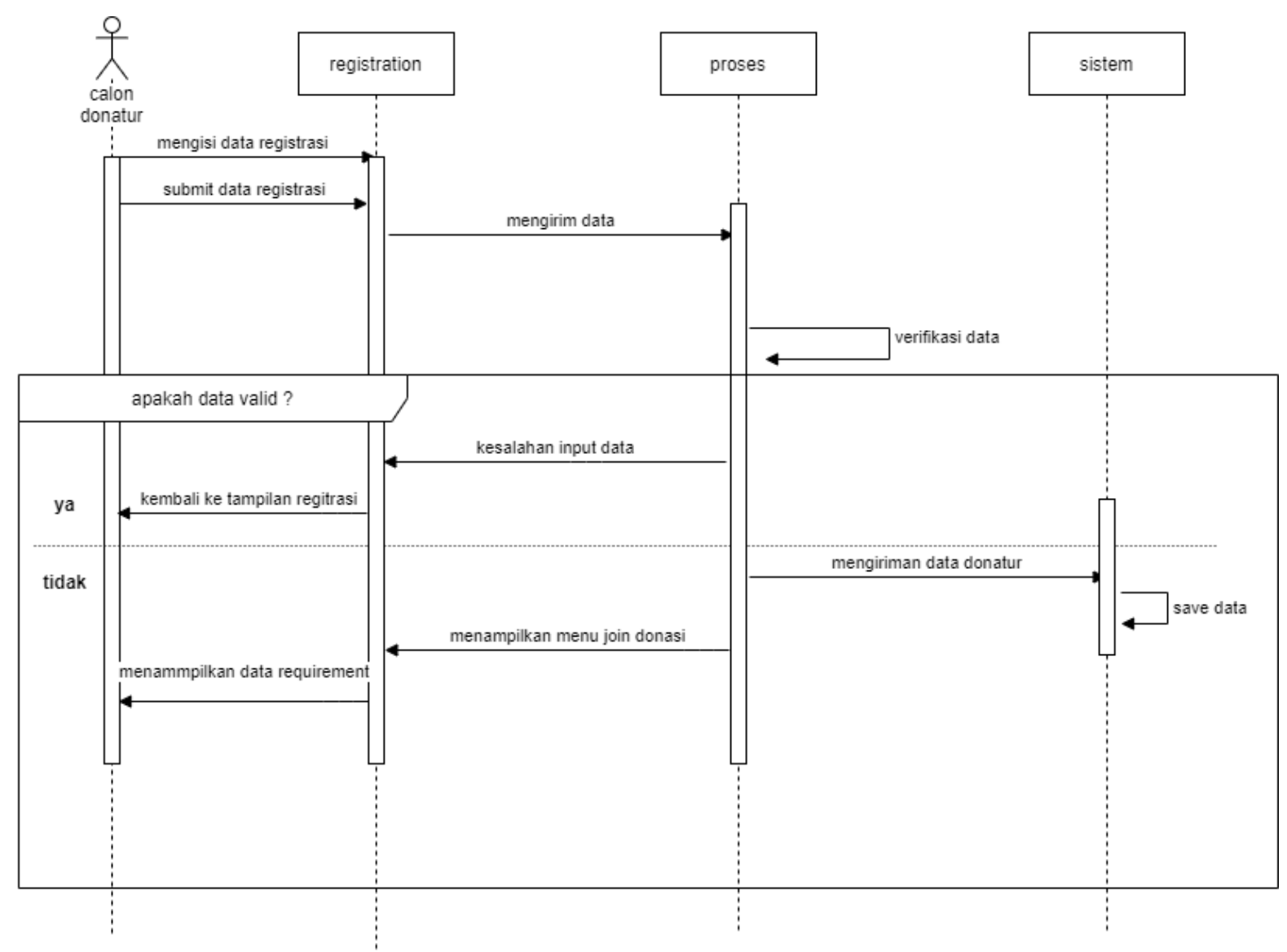

Figure 7 Gambar

\subsection{Interface Design}

-Interface Architecture, Interface Detailed Design (with screenshots), Provide the screenshots of the system

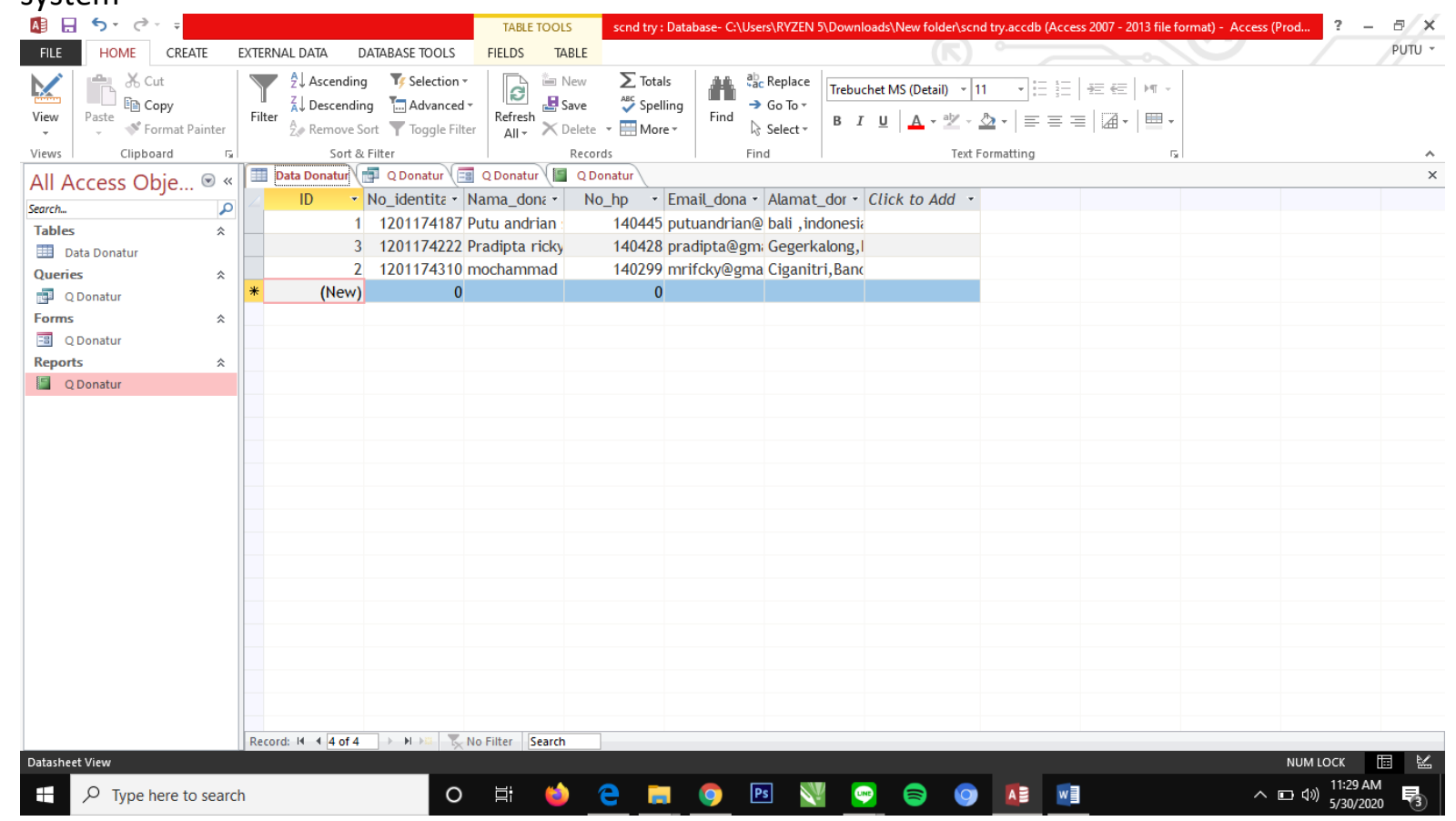

Figure 8 Table 


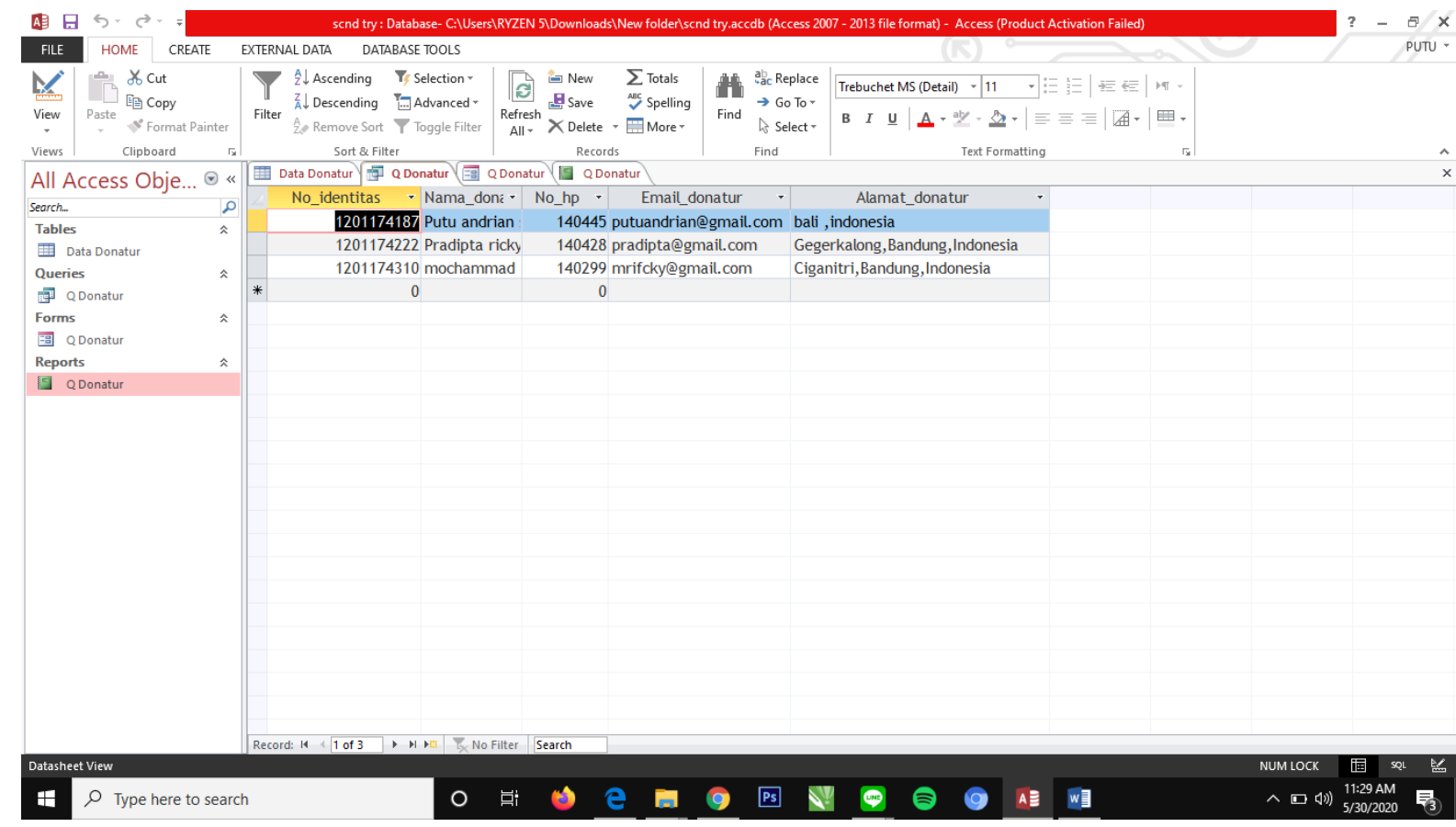

Figure 9 Queries

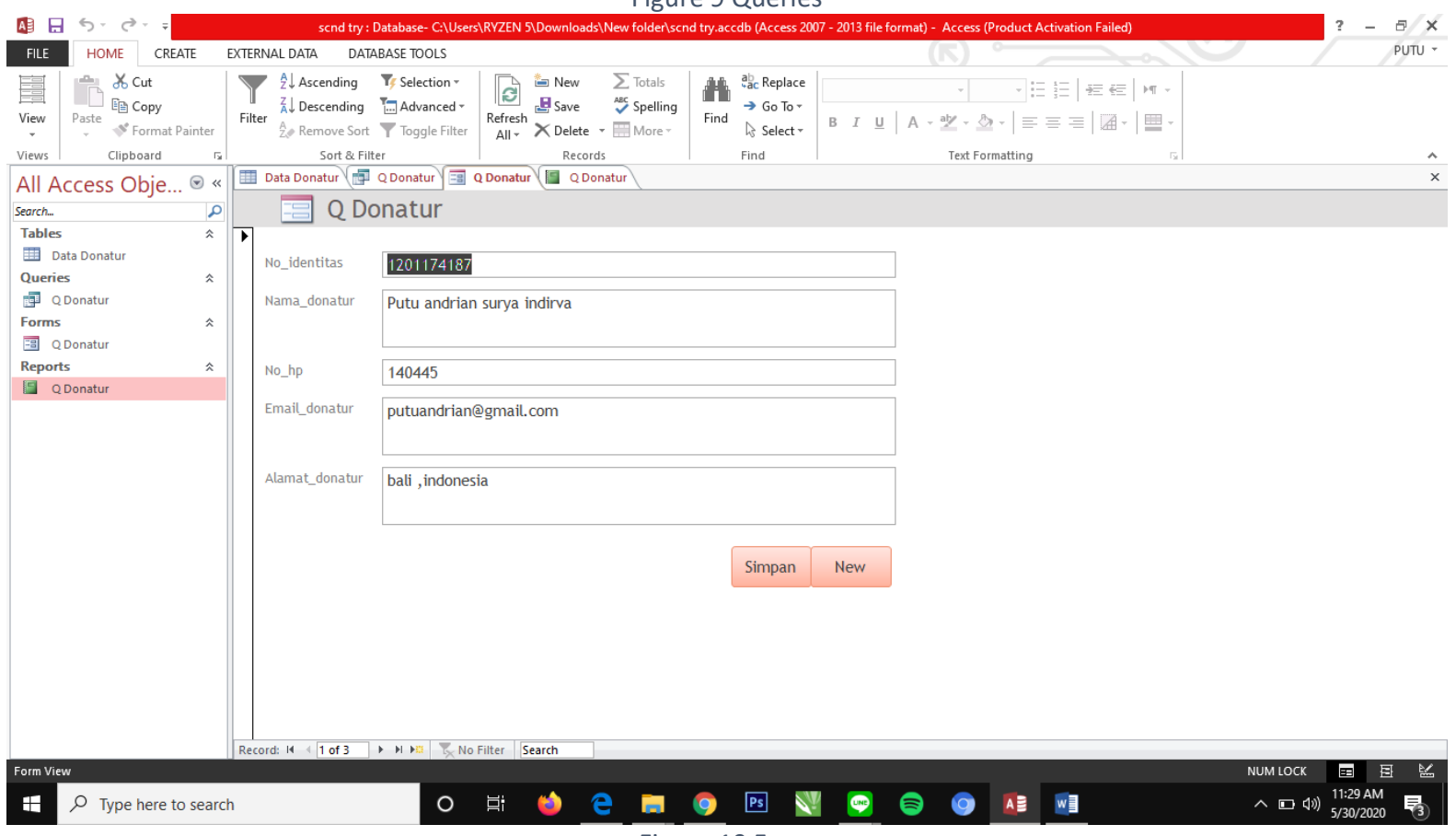

Figure 10 Form 


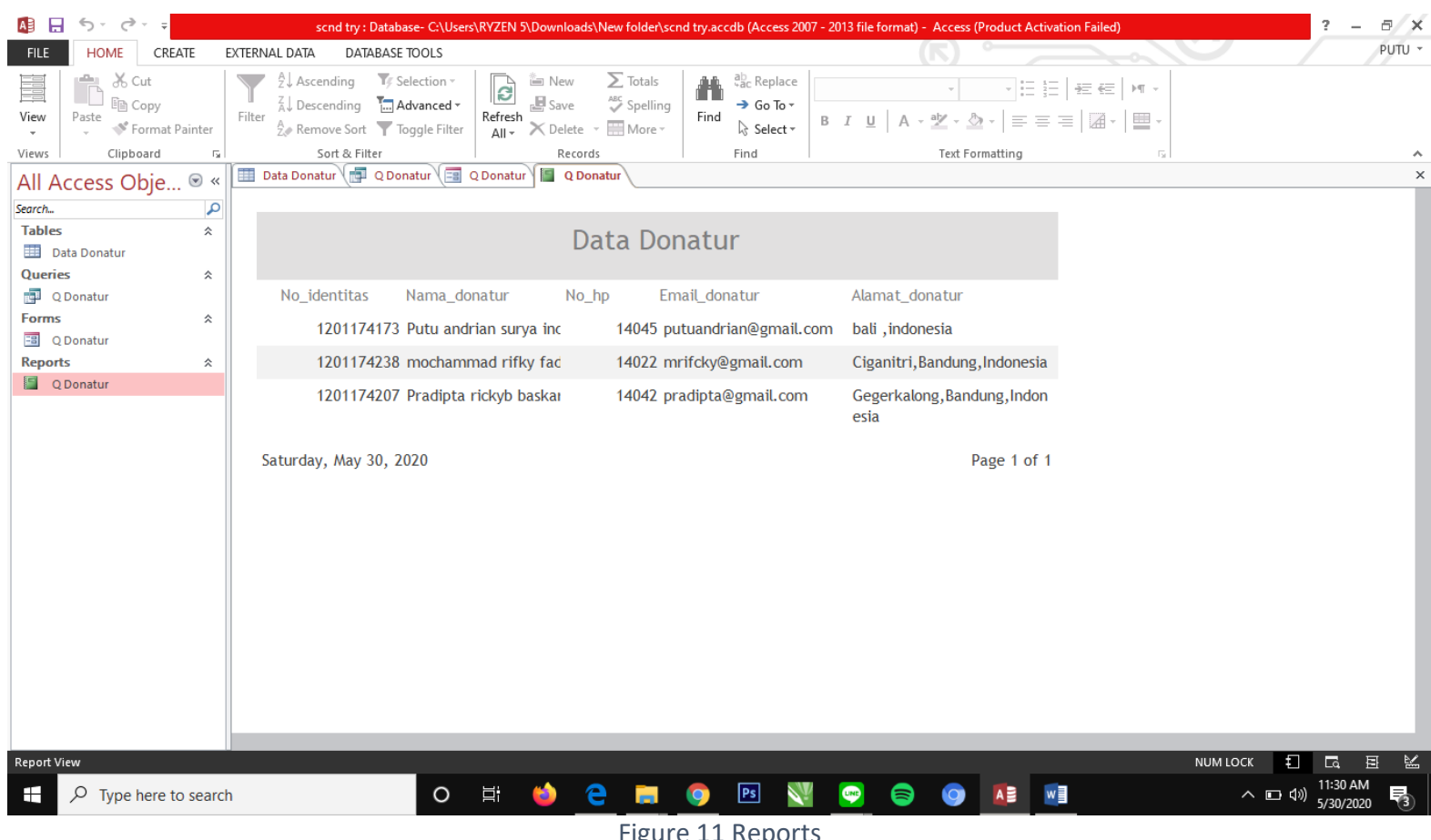

3.9 Source Code

Tuliskan penjelasan di sini

\section{Penutup}

4.1 Kesimpulan

Aplikasi ini digunakan untuk membantu proses penyaluran bantuan untuk para penyandang disabilitas agar lebih mudah, dengan demikian diharapkan aplikasi ini dapat pula membantu pemerataan bantuan untuk para penyandang disabilitas di Indonesia.

\subsection{Saran}

Sebaiknya aolikasi ini melakukan kerja sama dengan organisasi seperti organisasi masyarakat yang membantu kegiatan pengabdian kepada masyarakat agar sosialisasi dan kegunaan aplikasi ini dengan mudah di pahami terutama pada kondisi-kondusi penting.

\section{References}

[1] R. Aurachman, "Review Terhadap OSF.IO Sebagai Sarana Publikasi Preprint," OSF Preprints, 17 May 2020.

[2] R. Aurachman, "Kerangka Perancangan Sistem Informasi Sebagai Pembelajaran Mahasiswa Teknik Industri," osf.io, 52020.

\section{Additional}

[a] R. Aurachman, "Review Terhadap OSF.IO Sebagai Sarana Publikasi Preprint," OSF Preprints, 17 May 2020. doi:10.31219/osf.io/rvumx , Available: https://osf.io rvumx

[b] R. Aurachman, "Kerangka Perancangan Sistem Informasi Sebagai Pembelajaran Mahasiswa Teknik Industri," osf.io, doi:10.31219/osf.io/tmpcn , 5 2020. Available: https://osf.io/tmpen 
